\title{
Chronic fatigue syndrome in children and adolescents ${ }^{\dagger}$
}

\section{General practitioners' experience of the problem and their views about its treatment}

\author{
Josephine Richards and Frank Smith
}

\begin{abstract}
General practitioners in a south London health authority were sent a questionnaire about their experience and views concerning the treatment of childhood chronic fatigue syndrome. Most thought childhood chronic fatigue syndrome had a significant psychological component, but opinion was divided over referral to a psychiatrist. The involvement of self-help organisations was supported but the place of rest and exercise unclear. The optimum primary care management of childhood chronic fatigue syndrome needs to be establlished.
\end{abstract}

A recent report on chronic fatigue syndrome advocated that young patients should usually be managed within a primary care setting, but noted there was limited epidemiological information about the disorder in this age group (Royal College of Physicians, Royal College of Psychiatrists and Royal College of General Practitioners, 1996). The report was partially commissioned because of divided professional and public opinion regarding aetiology and treatment (Franklin, 1995; Wessely et al, 1989).

Childhood chronic fatigue syndrome is an emotive area, and has received increasing media publicity following a conference and a national television feature in 1996 (Bassindale, 1996). It became front page news in the Guardian in May 1997 under the headline "Schools swept by ME plague" (Boseley, 1997) after the publication of a school survey (Dowsett \& Colby, 1997). In the wake of the news coverage of Dowsett \& Colby's paper, Godlee (1997) highlighted the problem of weak research into the subject receiving prominence and uncritical appraisal even in serious newspapers, and Marcovitch (1997) reviewed the current treatment of chronic fatigue syndrome. He made a plea for more research into the educational needs of children with this disorder.

'See editorial pp. 193-194 and 198-202, this issue.
Our clinical experience suggested that childhood chronic fatigue syndrome is not universally recognised by general practitioners (GPs), and there is confusion over its treatment. Therefore we aimed to determine the number of young patients diagnosed as having chronic fatigue syndrome by a sample of GPs, and to examine these doctors' views about the aetiology and treatment of the disorder.

\section{The study}

All 332 GPs working in Merton, Sutton and Wandsworth Health Authority serving a population of 668610 (of whom $20.6 \%$ were aged 0-18), were posted a previously piloted questionnaire. The questionnaire asked about their experience, views concerning aetiology, and treatment preferences, in patients under 19 years old with chronic fatigue syndrome. They were supplied with a definition of the disorder based on the presence of severe fatigue, sufficient to interfere significantly with normal school and social functioning. The definition excluded those with an organic illness that could explain their symptoms, and fatigue of less than two months. We agreed with Carter et al (1995) that given children and young people's rapid emotional, social and academic growth, a two month minimum duration criterion seems appropriate. As in Sharpe et ats (1991) definition, patients with a current diagnosis of schizophrenia, manic-depressive illness, substance misuse, eating disorder or a proven organic brain syndrome were excluded but not those with a depressive illness or anxiety disorders.

The GPs were asked to list the cases they had personally diagnosed during the past 12 months, excluding those diagnosed by other doctors in the practice, and to estimate the Registrar General's social class category for each case. They were then asked for their views on 11 
possible treatments, derived from the medical and psychiatric literature (Wessely et al, 1989; Cox et al, 1991; Vereker, 1992) as well as publications produced by self-help groups (Franklin, 1995; Westcare, 1994) using fivepoint Likert scales.

The GPs were asked their age and gender, place of medical training, year of full registration with the General Medical Council, and their experience of any post-registration posts in psychiatry. They were also asked about their own personal experience of chronic fatigue syndrome, defined on a four-point scale from non-existent to extensive, dependent on their personal, family's, friends' or acquaintances' experiences. They were asked if they believed childhood chronic fatigue syndrome occurred. If they answered no, or undecided to this question, they were asked what diagnosis they would apply to a child presenting with the symptoms given in the definition, and how would they treat them. The results were analysed using the Statistical Package for the Social Sciences using chisquared analysis.

\section{Findings}

Two hundred and twenty-five completed questionnaires were returned after three mailings, giving a response rate of $68 \%$. The respondents had a mean age of 44 years (s.d. 10), $45 \%$ were women, $73 \%$ were UK trained and $29 \%$ had worked in a psychiatric post. Data drawn from Merton, Sutton and Wandsworth Health and national surveys (Kendrick et al, 1991; Merton, Sutton and Wandsworth Health, 1995) showed that the respondents were not significantly different in terms of age, place of qualification and past psychiatric experience from nonrespondents but contained more women than the Merton, Sutton and Wandsworth average (37\%). Respondents' personal experience of chronic fatigue syndrome was extensive or moderate in $10 \%(23 / 225)$, and slight or nonexistent in $75 \%(170 / 225$, missing values $15 \%$, 32). Fifty-two per cent (116) felt the syndrome occurs in this age group, $16 \%$ (36) did not and $31 \%(70)$ were undecided (missing data $1 \%, 3$ ).

Eighty-three cases had been diagnosed over the previous 12 months. In 59 cases the Registrar General's social class was recorded, and of these the largest number was recorded in class III $(26 / 59)$ but the cases were spread between all groups. Twenty-two per cent (51) of respondents had diagnosed at least one case within the previous 12 months. Doctors diagnosing cases were not different in terms of age, gender, year or place of qualification to those who did not diagnose cases. The presence or absence of personal experience was not signifcantly associated with case diagnosis. Only one respondent regarded chronic fatigue syndrome as primarily a physical disorder, the remainder perceiving it as either a psychological disorder $(15 \%, 33)$ or a combination of a psychological and physical disorder $(70 \%, 156)$, (missing data $15 \%, 35)$. The doctors $(16 \%, 36)$ who did not believe chronic fatigue syndrome existed in this age group did not give an alternative diagnosis to the symptom complex. Their management of such cases was usually to obtain a paediatric or medical opinion dependent on age.

Table 1 summarises the degree of agreement with the 11 statements about treatment. Missing data were classified as undecided. Opinion was evenly divided about the advisability of rest, home tuition, and psychiatric referral, although three-quarters supported an encouragement of school attendance and an increase of activity. A majority of respondents favoured obtaining a paediatric or medical opinion and the involvement of self-help organisations. Most were undecided about the value of magnesium supplements and evening primrose oil but a sizeable minority (34\%) of respondents favoured the use of antidepressants. This latter opinion was significantly more common among older ( $>45$ years), and male doctors $(P=0.0005,0.046$, respectively).

\section{Comment}

The report by the Royal College of Physicians, Royal College of Psychiatrists and Royal College of General Practitioners (1996) highlighted the need for further research in children and adolescents with chronic fatigue syndrome. There have been no studies specifically examining chronic fatigue syndrome among young patients within primary care or community samples in this country, and the two community studies recently performed surveyed patients over 18 (Lawrie \& Pelosi, 1995; Wessely et al, 1997). Ho-Yen \& McNamara (1991) conducted a questionnaire survey of GPs in Scotland covering a population of 218000 . They achieved a $95 \%$ response rate, and found 30 cases aged under 20.

Wessely et al (1997) have drawn attention to the significant problems of relying on GP key informant surveys, given that most patients are not identified by either themselves or the GP. Only a small proportion of adult patients within a primary care setting who fulfil the diagnostic criteria for chronic fatigue syndrome use this term to describe their illness (Euba et al, 1996). GPs may be more ready to diagnose when selfdiagnosis has already been made (Scott et al, 1995). Our survey did not explore how many 
Table 1. Percentage responses to suggested treatment options in childhood chronic fatigue syndrome

\begin{tabular}{|c|c|c|c|}
\hline & Agree & Undecided & Disagree \\
\hline \multicolumn{4}{|l|}{ Statements with which most GPs agreed } \\
\hline School attendance should be encouraged & 77 & 21 & 2 \\
\hline All activities should gradually be increased & 73 & 22 & 5 \\
\hline $\begin{array}{l}\text { A paediatric/medical opinion (depending } \\
\text { on age) is usually indicated }\end{array}$ & 67 & 26 & 6 \\
\hline $\begin{array}{l}\text { Involvement of self-help organisations is } \\
\text { to be encouraged }\end{array}$ & 61 & 32 & 7 \\
\hline \multicolumn{4}{|c|}{ Statements with which most GPs were undecided, but more disagreed than agreed } \\
\hline Magnesium supplements are helpful & 9 & 70 & 21 \\
\hline $\begin{array}{l}\text { Evening primrose oil/gamma linoleic acid } \\
\text { is an effective treatment }\end{array}$ & 7 & 59 & 34 \\
\hline $\begin{array}{l}\text { For many patients increasing physical activity is } \\
\text { harmful }\end{array}$ & 11 & 50 & 39 \\
\hline Antidepressant medication is rarely indicated & 18 & 48 & 34 \\
\hline \multicolumn{4}{|l|}{ Statements with which opinion was evenly divided } \\
\hline The patient should be encouraged to rest & 32 & 34 & 33 \\
\hline Most patients should see a psychiatrist & 40 & 35 & 25 \\
\hline Home tutoring should be encouraged in many cases & 25 & 40 & 35 \\
\hline
\end{tabular}

1. Sample size 225, missing values classified as undecided.

cases were self-diagnosed by the patient or their families.

Chronic fatigue syndrome is conceptualised by our respondents as having a substantial psychological component but their views as to whether patients should see a psychiatrist were mixed. The effectiveness of psychological treatments for adults has been demonstrated in a number of studies (Sharpe et al, 1996). Whether such treatments can be instituted in a primary care setting, as is suggested for the majority of patients with chronic fatigue syndrome by the Royal Colleges' report (Royal College of Physicians, Royal College of Psychiatrists and Royal College of General Practitioners, 1996), is open to debate. These patients present GPs with considerable difficulties (Scott et al, 1995), and they and their families may be reluctant to attend for a psychiatric appointment even though psychiatric symptoms, such as depression, are often present (Walford et al, 1993). Such issues may be reflected in the lack of agreement amongst GPs in our survey as to whether a psychiatrist should become involved.

Although only one GP in this sample regarded chronic fatigue syndrome as primarily a physical disorder the majority of respondents favoured a paediatric or medical opinion. This finding might reflect patient and parental views that organic factors are involved, or the doctors' desires to investigate thoroughly and not miss a physical disorder. However, the Royal Colleges' report warns against overinvestigation and belated consideration given to social and psychological factors.

Self-help organisations were strongly favoured in this survey although there is some evidence to suggest their involvement is associated with a poorer outcome (Sharpe et al, 1996). It seems likely that this group of GPs was not fully aware of the advice given by support groups who strongly advise home tuition in many cases (Franklin, 1995) as they felt that school attendance should be encouraged, and were divided over the place of home tuition.

The respondents' views about the need to rest and whether to increase activities were conflicting. A randomised controlled trial of graded exercise in adult chronic fatigue syndrome was successful in reducing symptoms at a 12-week follow-up (Fulcher \& White, 1997), lending weight to the rehabilitation programmes outlined for children that incorporate graded exercise (Wachsmuth \& Macmillan, 1991; Vereker, 1992). Wessely et al (1989) feel that the avoidance of activity leads to demoralisation and depression, promoting chronic disability. Our survey suggests that the majority of these GPs support graded exercise, but there is disagreement over the place of rest.

It seems important that patients and their families are given clear messages from doctors about the need to gradually increase their activity levels and minimise their absence from school. 


\section{Acknowledgement}

This study was supported by a grant from Lilly Industries, covering the cost of the questionnaire.

\section{References}

BAssindale, C. (1996) The ME generation. Evening Standard, 23 April, 27.

BOSELEY, S. (1997) Schools swept by ME plague. Guardian, 22 May, 1.

CARTER, B. D., EdWARds, J. F., KRONEnBerger, W. G., et al (1995) Case control study of chronic fatigue patients in pediatric patients. Pediatrics, 95, 179-186.

CoX. I. M., CAmpBell, M. J. \& Dowson, D. (1991) Red blood cell magnesium and chronic fatigue syndrome. Lancet, 337, 757-760.

DOWSETT, E. G. \& COLBY, J. (1997) Long term sickness absence due to ME/CFS in UK schools: an epidemiological study with medical and educational implications. Journal of Chronic Fatigue Syndrome, 3. $29-42$.

Euba, R., Chalder, T., Deale, A., et al (1996) A comparison of the characteristics of chronic fatigue syndrome in primary and tertiary care. British Journal of Psychiatry. 168, $121-126$.

FrANKLIN, A. (1995) Children with ME. Guidelines for School Doctors and General Practitioners. Stanford-le-Hope: Myalgic Encephalomyelitis (ME) Association.

FULCHER, K. \& WHITE, P. (1997) Randomised controlled trial of graded exercise in patients with the chronic fatigue syndrome. British Medical Journal, 314, 1647-1652.

GodleE, F. (1997) Plague or pure hype? British Medical Journal, 314, 1700.

HO-YEN, D. O. \& MCNAMARA, I. (1991) General practitioners experience of the chronic fatigue syndrome. British Journal of General Practice, 41, 324-326.

KENDRICK, T., SiBBALD, B., BURNS, T., et al (1991) Role of general practitioners in care of long term mentally ill patients. British Medical Joumal, 302, 508-510.

LAWRIE, S. M. \& PELOSI, A. J. (1995) Chronic fatigue syndrome in the community: Prevalence and associations. British Journal of Psychiatry, 166, 793-797.

MARCOVITCH, H. (1997) Managing chronic fatigue syndrome in children. British Medical Joumal, 314, 1635-1636.

MERTON, SUTTON AND WANDSWORTH HEALTH AUTHORTY (1995) Directory of General Practitioners. London: MSWHA.
Royal College of Physiclans, Royal COLlege of PSYCHIATRISTS AND ROYAL COLLEGE OF GENERAL PRACTITIONERS (1996) Chronic Fatigue Syndrome. Report of a joint working group of the Royal Colleges of Physicians, Psychiatrists and General Practitioners (Council Report CR54). London: Royal College of Physicians.

SCOTt, S., DEARY, I. \& PELOSI, A. J. (1995) General practitioners' attitudes to patients with a self diagnosis of myalgic encephalitis. British Medical Journal, 310, 508.

SHARPE, M., HAWTON. K., SimkIn, S., et al (1996) Cognitive behaviour therapy for the chronic fatigue syndrome: a randomised controlled trial. British Medical Joumal. 312. 22-26.

SHARPE. M. C., ARChARD, L. C., BANATVALA, J. E., et al (1991) A report-chronic fatigue syndrome: guidelines for research. Journal of the Royal Society of Medicine, 84. 118-121.

VEREKER. M. I. (1992) Chronic fatigue syndrome: a joint paediatric-psychiatric approach. Archives of Disease in Childhood, 67, 550-555.

WACHSMUTH, J. R. \& MACMILAN, H. L. (1991) Effective treatment for an adolescent with chronic fatigue syndrome. Clinical Paediatrics, 30, 488-490.

WALFORD, G. A., MCNelson, W. \& MCClusky, D. R. (1993) Fatigue, depression and social adjustment in chronic fatigue syndrome. Archives of Disease in Childhood, 68. 384-388.

Wessely, S., Chalder, T., Hirsch, S., et al (1997) The prevalence and morbidity of chronic fatigue and chronic fatigue syndrome: a prospective primary care study. American Journal of Public Health, 87, 1449-1455.

-. DAVID, A., BUTLER, S., et al (1989) Management of chronic (post-viral) fatigue syndrome. Journal of the Royal College of General Practitioners, 39, 26-29.

WESTCARE (1994) Report from the National Task Force on Chronic Fatigue Syndrome, Post Viral Fatigue Syndrome, Myalgic Encephalomyelitis. Bristol: Westcare.

Josephine Richards, Senior Registrar, Section of Child and Adolescent Psychiatry, and *Frank Smith, Senior Lecturer in General Practice and Primary Care, Section of Child Mental Health, Department of General Psychiatry, Jenner Wing, St George's Hospital Medical School, Cranmer Terrace, Tooting, London SW17 ORE

*Correspondence 